\title{
Does the Cognitive-Behavioural Model of Learning share features of Buddha's and Krishnamurti's Teachings? Using the Concept of Automatic Maladaptive Thoughts as an Example
}

\author{
Rosangela Bertelli \\ Universidade de Trás-os-Montes e Alto Douro \\ Escola de Ciências Humanas e Sociais \\ Quinta de Prados, 5001-801 \\ Vila Real, Portugal
}

\begin{abstract}
Underneath the cognitive-behavioural interventions is the therapeutic process of learning to identify one's flows of automatic cognitions, bringing those to one's level of consciousness. Underneath the teachings of the Buddha (Dharma/Dhamma) is the therapeutic process of learning to meditate, allowing one to recognise one's awareness and calming down one's mind. Underneath the teachings of J. Krishnamurti is the therapeutic process of learning vigilant attentiveness to understand one's structure and movement of thought, allowing one to go beyond it. Do cognitive-behavioural interventions share features of Buddha's and Krishnamurti's teachings? The present article, using the concept of automatic maladaptive thoughts as an example, compares the three therapeutic processes. Results obtained brought out that the cognitivebehavioural, Buddha's and Krishnamurti's models of learning all conceptualise "thought" as mechanical and conditioned, and responsible for originating maladaptive emotions. Also, a curative for "automatic maladaptive thoughts" can only be found in an alert cognitive state in which one is aware of oneself, of one's situation, and of one's conditioned thought forms, emotions, and actions.
\end{abstract}

Keywords: Cognitive-Behavioural Learning, Buddhism, Krishnamurti's Teachings, Automatic Maladaptive Thoughts

\section{INTRODUCTION}

Cognitive-behavioural interventions are evidence based practices that permit one to attain some steadiness of mind [1]. On the other hand, spiritual practices do benefit those who do them in finding calmness of the mind [2]. Among those practices that try to look beyond the measurable are the teachings of the Buddha (Dharma/Dhamma) and the teachings of J. Krishnamurti.

Those three practices imply a process of learning that will ultimately contribute to healing or to some kind of change that will reveal a contented state of being healthy. Do cognitivebehavioural interventions share features of Buddha's and Krishnamurti's teachings?

The aim of this article is to look into each of the three theoretical accounts and, considering the notion of automatic maladaptive thoughts, verify whether they share some features.

\section{Cognitive-Behavioural Model of Learning}

According to the cognitive-behavioural approach, one's thoughts exert a controlling influence over one's emotions and over one's behaviours. Such behaviours, on the other hand, exert a controlling influence over one's emotions and over one's thoughts. Thoughts and behaviours condition each other in a controlling mechanical way through a process of learning where the emotions elicited by one's thoughts, on the one hand, and by one's behaviours, on the other 
hand, lead one's behaviours to become dependent on the occurrence of certain thoughts that flow in certain circumstances and one's thoughts to become dependent on the occurrence of certain behaviours that are emitted in certain circumstances.

That dynamic shapes one's functioning in terms of one's thoughts, emotions, and behaviours creating motion patterns associated to specific circumstances in a vicious cycle where one trouble (for instance, automatic maladaptive thoughts) leads to another trouble (for instance, dysfunctional emotions and behaviours) that aggravates the former (automatic maladaptive thoughts).

One's behaviours can thus be a dependent variable, dependent on the thoughts that occur in certain circumstances, and at the same time, one's behaviours can be an independent variable in the presence of which, in certain circumstances, some particular thoughts will flow. One way or another, associated emotions will be elicited and the chain between thoughts and behaviours will be fastened, tightened and secured.

Automatic/mechanically maladaptive thoughts are knowledge (schemata resulting from negative life experiences) or everything that is known by a person that flows speedily and automatically through one's mind as one goes about his/her every day or circumstances. Such thoughts, automatic/mechanically maladaptive thoughts, elicit or call forth emotions, feelings, and responses.

Because those thoughts are negative, dysfunctional, failing to serve an adjustive purpose, automatic/mechanically maladaptive thoughts elicit equally impaired emotions that lead to maladaptive behaviours towards one self, towards the one's around, and towards everything that exists anywhere.

One is able to learn self-help abilities through a process of identification, recognition or acknowledgment of automatic/mechanically maladaptive thoughts, where one first learns how to use differing written registers of streaming of thoughts pouring one's mind during difficult situations and those thoughts related emotions. Such procedures make it possible for the person to discover one's own patterns of automatic/mechanically maladaptive thoughts, allowing one to discern, perceive, or know and comprehend the nature or meaning of one's own relevant cognitions $[3,4,5,6,7]$.

\section{The Teachings of the Buddha (Dharma/Dhamma)}

According to Buddhism (or the teachings of Buddha Gotama), humankind has a mind that presents a restless moving pattern that sets off thoughts, feelings, and behaviours which give rise to confusion or perplexity and that keeps agitating one's mind. Such pattern of uneasiness puts in motion automatic maladaptive thoughts and feelings prompting certain forms of behaviours in certain circumstances.

When one identifies oneself with those automatic maladaptive thoughts and feelings, one turns attached, fond and affectionate to those conceptual images of who one supposedly is. In other words, one becomes tied to memories of past events, to one's own pain, to one's choleric feelings, to how one visualises, conceives of or sees oneself in one's mind, tied to who one thinks he/she is, to one's associations with how one was hurt in the past or on how one destroyed or ruined the life to others.

Identifying oneself with one's automatic maladaptive thoughts and feelings means that one becomes attached to the past by identifying oneself with all past circumstances, old tormenting 
thoughts about the past, because all of those things paint a perfect picture of whom one believes he/she is. The mind, thus, takes on a fixation and follows or complies with one's automatic maladaptive thoughts, negative emotions and regretful behaviours.

Such restlessness and connectedness contribute to a lot of self-created problems or psychological suffering such as a tendency to notice shortcomings and to keep on focusing on those automatic maladaptive thoughts. Negative life experiences look for problems, even small ones, transforming any problem into a huge catastrophe. In sum, as a consequence, circumstances tend to be misinterpreted according to those bent thoughts, that is, according to thoughts shaped by mental constructs derived from specific instances or abstract ideas about who one thinks he/she is.

According to Buddhism, meditation is the way to get to know how one's mind works, allowing one's mind to rest and go still, because when automatic maladaptive thoughts and feelings stop stirring up the mind, letting it rest, everything goes still and becomes clear. Meditation allows one to observe one's own flow of automatic/mechanically maladaptive thoughts and feelings, without interpreting, judging, or commenting on them, and to see how one's mind creates problems, misperceptions, and generates emotions and behaviours.

Knowing how one's mind works is called wisdom. Wisdom arises from silence, not from thinking, but from a quiet mind. The goal of mediation is silence, stillness, clarity of the mind making it possible to learn how to watch thoughts and feelings go by, float by and the mind to rest. The effort is directed to discover, letting go, to developing a mind that inclines to abandoning, to renouncing.

One understands how one's mind works, becomes aware, accepts it, let go, make peace with defilements and hindrances. Meditation is not about how to change one's mind, but about how to accept one's mind and on how to recognise awareness, wisdom, finding good qualities inside one self, such as gratitude, generosity, forgiveness, compassion [8, 9].

\section{The Teachings of J. Krishnamurti}

According to the teachings of Jiddu Krishnamurti [10], an Indian philosopher, from very early childhood a child begins to be told who he/she is, for instance, one's attributes, distinguishing qualities (physical, psychological, emotional, behavioural, and societal), who the child should become and, consequently, the child soon begins to be compared to others. Parents, teachers, the whole family and society as a whole do that, even comparing a child with other children through numerical classifications. Comparisons hurt and these kinds of experiences carve in the child's mind an iconic mental representation of who he/she is and then thought arises, automatic maladaptive thoughts.

A hurt bound child's thoughts are automatic maladaptive thoughts. Hurt bound thoughts elicit hurt bound emotions that elicit hurt bound behaviours. Psychological suffering forms then the boundaries of one's thinking, feelings, behaviours, making one prone to misjudge circumstances.

Thoughts create conflicts (within one self and between people) and one is always trying to escape from those conflicts. In such attempts to getting away one builds up an image of one self. That image is sustained by thought, automatic maladaptive thoughts, that bring uneasiness. One suffers because having an image about one self cause psychological damage or affects negatively one's own image. 
One's mind will always endure conflicts between what one is and what one wants to be, between the real and the ideal, between what is and the myth of what should have being. Automatic maladaptive thoughts will contribute to dysfunctional emotions and consequent maladaptive behaviours. Such process leads to the shaping of a person's thoughts and the thoughts that arise are not innocent, that is, they already are thoughts of a psychologically hurt mind.

One will only become able to perceive something immense, immeasurable, impossible to express as a number or quantitative data by means of a state of peace, quiet, tranquillity, and an untroubled mind. Such steadiness of the mind allows one to pay attention to what goes on inside one's mind. Knowing and comprehending the nature or meaning of one's mind contents is vitally necessary in order to go beyond it. One must understand one's own suffering or, in other words, the nature of one's psychological hurt.

The hurts can be healed and future hurts can be kept from happening. The mind must though be attentive, without looking for thought, and understand the dysfunction, because out of the understanding of the hurts and out of the understanding of the image comes the active attention [10]. The mind must be capable of paying quiet attention, capable of attaining, listening, seeing, and perceiving beyond the mechanical, perceiving the immeasurable.

Table 1 presents the set of features shared by the cognitive-behavioural model of learning, the teachings of the Buddha, and the teaching of J. Krishnamurti. Starting out from the constructs of "thought", "automatic thought", and "maladaptive thought", Table 1 synthesises the main overlapping points among them.

Table 1. Features shared by Cognitive-Behavioural, Buddhism, and Krishnamurti's Models of Learning

\begin{tabular}{|c|c|c|c|}
\hline $\begin{array}{c}\text { Automatic } \\
\text { Maladaptive } \\
\text { Thoughts } \\
\end{array}$ & Cognitive-Behavioural & Buddhism & $\begin{array}{l}\text { Krishnamurti's } \\
\text { teachings }\end{array}$ \\
\hline Thought is & $\begin{array}{l}\text { Mechanical and } \\
\text { conditioned }\end{array}$ & $\begin{array}{l}\text { Mechanical and } \\
\text { conditioned }\end{array}$ & $\begin{array}{l}\text { Mechanical and } \\
\text { conditioned }\end{array}$ \\
\hline $\begin{array}{l}\text { When thought is } \\
\text { operating }\end{array}$ & $\begin{array}{l}\text { Maladaptive emotions } \\
\text { arise }\end{array}$ & $\begin{array}{l}\text { Maladaptive emotions } \\
\text { arise }\end{array}$ & $\begin{array}{l}\text { Maladaptive emotions } \\
\text { arise }\end{array}$ \\
\hline Thought focuses on & $\begin{array}{l}\text { Negative information and } \\
\text { consequent maladaptive } \\
\text { emotions }\end{array}$ & $\begin{array}{l}\text { Negative information and } \\
\text { consequent maladaptive } \\
\text { emotions }\end{array}$ & $\begin{array}{l}\text { Negative information } \\
\text { and consequent } \\
\text { maladaptive emotions }\end{array}$ \\
\hline How to remedy? & $\begin{array}{l}\text { Paying active attention to } \\
\text { those } \\
\text { automatic maladaptive } \\
\text { thoughts; } \\
\text { Become aware of their } \\
\text { structure and movement; } \\
\text { Acknowledge their } \\
\text { existence. }\end{array}$ & $\begin{array}{l}\text { Paying active attention to } \\
\text { those } \\
\text { automatic maladaptive } \\
\text { thoughts; } \\
\text { Become aware of their } \\
\text { structure and movement; } \\
\text { Acknowledge their } \\
\text { existence. }\end{array}$ & $\begin{array}{l}\text { Paying active attention } \\
\text { to those } \\
\text { automatic maladaptive } \\
\text { thoughts; } \\
\text { Become aware of their } \\
\text { structure and } \\
\text { movement; } \\
\text { Acknowledge their } \\
\text { existence. }\end{array}$ \\
\hline Effects & $\begin{array}{l}\text { Out of consciousness* } \\
\text { comes the watchfulness. }\end{array}$ & $\begin{array}{l}\text { Out of consciousness* } \\
\text { comes the watchfulness. }\end{array}$ & $\begin{array}{l}\text { Out of consciousness* } \\
\text { comes the watchfulness }\end{array}$ \\
\hline
\end{tabular}

*Consciousness $=$ An alert cognitive state in which one is aware of oneself, of one's situation, and of one's conditioned thought forms, emotions, and actions.

\section{DISCUSSION}

The present article, using the concept of automatic maladaptive thoughts as an example, compares three apparently differing models of learning in order to answer the question: Does 
the cognitive-behavioural model of learning share features of Buddha's and Krishnamurti's teachings?

Results found that the three models, using not so dissimilar language, conceived of thought as a psychological result of perception, learning, reasoning, and as knowledge known, experienced. Thought creates thoughts, emotions, and behaviours, and it is the basis of one's reality. Thought is conceptual and conditioned. The movement, flow, streaming of thoughts creates thought forms in which one becomes entrenched. Thought also creates flows of negative emotions and focuses on flows of negative thoughts which create more negative emotions and dysfunctional behaviours. Thought is a narrative that tells one who one is, should be, and confirms one's produced identity.

The three models also considered that becoming knowledgeable of one's own flowing of thought and automatic maladaptive thoughts in particular would provide one with the necessary exemption from those thoughts, that is, from the conditioning, thus supplying one with the opportunity for watchfulness only to remain. How to develop such immunity from automatic maladaptive thoughts, emotions, and behaviours is another concern though.

According to the cognitive-behavioural model of learning, becoming aware of one's own thoughts, automatic/mechanically maladaptive thoughts, is just the first step in the process. The second step involves one's learning to use differing written registers of one's thoughts that are more consistent with reason, with rational thought. Such procedures would grant the person with the opportunity to examine the evidence in favour of or against those automatic maladaptive thoughts and also to conceive of and to give careful consideration to more constructive viewpoints.

Observing in written that one's thoughts or, in other words, that one's interpretation of one's circumstances (situations) are not necessarily real or in accordance with facts would give one a new perspective that would potentially, according to the cognitive-behavioural model of learning, lead to the restructuring of one's schemata, that is, one's knowledge ensuing from one's life experiences. Because schemata are the roots from where all automatic thoughts sprout, changing or reconstructing schemata would potentially alter one's mental representation of the meaning or significance of one's circumstances past and present. As a consequence of such remodelling, thoughts, emotions, and behaviours associated to certain circumstances would change, becoming more adaptive.

According to Buddhism (Dharma/Dhamma) though, only an empty mind can become aware. Awareness allows one to see the truth, to see how things actually are, and thus awareness is wisdom. Wisdom results in peacefulness and stillness of the mind. Out of consciousness comes the watchfulness that will simply let go of, will stop holding on to automatic maladaptive thoughts, emotions, and behaviours $[2,8,9]$.

According to the teachings of Krishnamurti, truly active attention, without looking for thought, will simply wipe up automatic maladaptive thoughts, which come from one's psychological hurts. In understanding the hurts and out of that understanding, attention will come and one's image of oneself will dissolve. Out of consciousness comes the watchfulness. One will understand and go beyond, and automatic maladaptive thoughts will disappear and thought will act only where it is necessary for one's survival. 


\section{CONCLUSION}

The cognitive-behavioural model of learning definitely shares features of Buddhism and Krishnamurti's teachings. Considering the quality of one of the key features shared by the three models, namely the notion that thought is mechanical, conditioned, triggers emotions, behaviours, and rewards itself, one wonder stands out in relation to the cognitive-behavioural interventions [4]: How come that the design of more thoughts (rational thoughts as intellectual answers to maladaptive automatic thoughts) would produce therapeutic results? What would be such a mechanism?

\section{References}

Beck, A. T., \& Dozois, D. J. A. (2011). Annual Review of Medicine, 62, 397-409. DOI: 10.1146/annurev-med-052209100032

Sheldrake, R. (2017). Science and spiritual practices: Reconnecting through direct experience. London: $\underline{\text { Coronet }}$ Books. ISBN 13: 9781473630093

Beck, A. T. (1991). Cognitive therapy and the emotional disorders. London: Penguin. ISBN 10: 0140156895

Beck, J. S. (1995). Cognitive behaviour therapy: Basics and beyond (2nd ed.). New York: The Guilford Press. ISBN 978-1-60918-504-6

Bertelli, R. (2017a). The effects of expressive arts on the evoking of automatic thoughts during the training at a graduate level of personal and professional development of cognitive-behavioural clinical psychologists: A qualitative study. Review of Arts and Humanities, 6(1), 7-11. Retrieved from http://rahnet.com/journals/rah/Vol_6_No_1_June_2017/2.pdf

Bertelli, R. (2017b). The generative process of professional and personal development of cognitive-behavioural clinical psychologists in training through the inclusion of strategies of expressive arts: A qualitative analysis and comparison. Journal of Arts \& Humanities, 6(8), 37-46. Retrieved from https://theartsjournal.org/index.php/site/article/view/1244/600

Bertelli, R. (2018). Expressive arts activities as tools to enhance the education of clinical psychologists: A qualitative study. Advances in Social Sciences Research Journal, 5(12), 476-481.

Retrieved from http://scholarpublishing.org/index.php/ASSRJ/article/view/5779/3551

Brahm, A. (2011). The art of disappearing: The Buddha's path to lasting joy. Somerville, MA: Wisdom Publications. ISBN 978-0-86171-668-5

Brahm, A. (2017). Bear awareness: Questions and answers on taming your wild mind. Somerville, MA: Wisdom Publications. ISBN 978-1-61429-256-2

Sydney M. Roth. (Producer). (1974, February 25th). On being hurt and hurting others. Jiddu Krishnamurti in Conversation \#11 with Dr Allan W. Anderson. San Diego, California. Retrieved from https://www.youtube.com/watch?v=I54SH0IbpzQ 